\title{
Mathematical justification of the wound suturing by wound contractors of new generation
}

\author{
S.G. Izmaylov ${ }^{1}$, A.I. Rotkov ${ }^{1}$, V.V. Beschastnov ${ }^{1}$, S.I. Rotkov ${ }^{2.3}$, E.V. Popov ${ }^{2}$, E.E. Lukoanychev ${ }^{1}$ \\ rotkov@nngasu.ru \\ ${ }^{1}$ GKB No. 35, Nizhny Novgorod, Russia; \\ ${ }^{2}$ Nizhny Novgorod State University of Architecture and Civil Engineering, Nizhny Novgorod, Russia; \\ ${ }^{3}$ ANO "Research Center for Physical and Technical Informatics", Nizhny Novgorod, Russia
}

\begin{abstract}
Frequent cases of man-made disasters, terrorist attacks and military conflicts lead to an increase in the number of victims. Significant soft tissue defects are known to result from gunshot wounds. So, as a result of mine-blasting injuries, defects in the skin and underlying tissues more than $10 \mathrm{~cm}$ in diameter are formed in $71.1 \%$ of cases. The prerequisite for the uncomplicated course of the wound process is to achieve an adequate comparison of the edges of the wound without excessive tension. To close such extensive wounds, various technical means are used: sutures on pads, various types of dermatotension. We have developed various models of wound contractors $(R C)$ for treatment of wounds. With the help of the $R C$, a complete reposition and good adaptation of the edges of the wound is created. The wound closure method using these RC almost completely eliminates tissue cutting and limits the sawing effect to a minimum. This is explained by the effects of elastic forces reducing to zero when matching soft tissues and suturing. The use of hardware methods for suturing wounds requires the development of mathematical models of various types of wounds and surgical sutures. These models should provide a simulation of living tissues of the wound edges behavior to achieve the best results in the treatment of wounds by RC advanced technologies. The purpose of this study is to mathematically justify $R C$ with the parallel holding of spokes. Another purpose is to develop a mathematical model of the wounds suturing by hardware technology.
\end{abstract}

Key words: wound suturing, wound contractors, spoke adaptation and reposition contractors, branch, adaptation and reposition apparatus.

\section{Introduction}

The mathematical justification of the spoke adaptationrepositional contractors (SPARC) and methods for suturing wounds was carried out by standard formulas and methods adopted in mechanics [1-3]. Mathematical calculation and formulas derivation were consulted by the assistant professor of the Department of Theoretical Mechanics of Kazan State University Tazyukova F.Kh. The wound mathematical model was developed together with Professor E.V. Popov and Professor S.I. Rotkov.

The experimental part of the work was performed on 18 outbred dogs, weighing $14.5 \pm 0.7 \mathrm{~kg}$, which were divided into two groups: experimental (hardware method of suturing) and control (traditional method of suturing). An extensive granulating wound was modeled according to the method of V.I. Struchkov (1975) in our modification.

In order to reduce the morbidity of stitched tissues, we used a spoke (Sp) adaptation-reposition apparatus (ARA)
(SPARC-III) that we developed to bring the edges of the granulating wound closer in the animals of the main group. This device for converging the wound edges is protected by Patent for invention No. 2214797, filed January 8, 2002 and published on October 27, 2003 in Bulletin No. $30 \mathrm{~S}$. G. Izmaylov, V. V. Beschastnov, A. A. Bodrov, M. N. Kiselev, M.N. Kudykin. (A positive FIPS decision on the grant of a patent of the Russian Federation dated 01/18/02. On the application for invention No. 2002100973). The device contains two branches (Fig. 1), a rack-and-pinion drive and spokes, characterized in that the spokes are made in the form of curved surgical spokes, comprising $1 / 2-5 / 8$ of the diameter of the circle and installed with the possibility of fixation by presoft tissueated branches made of two corrugated plates on internal surfaces. In this case, one of the plates is removable, and in the end part of the other, a turnkey 3- or 4-sided groove is made for alternately turning the branch in the cylindrical sockets of the rack-and-pinion drive, which is equipped with screw clamps for turning the branches, which can be fixed by rails to each other.

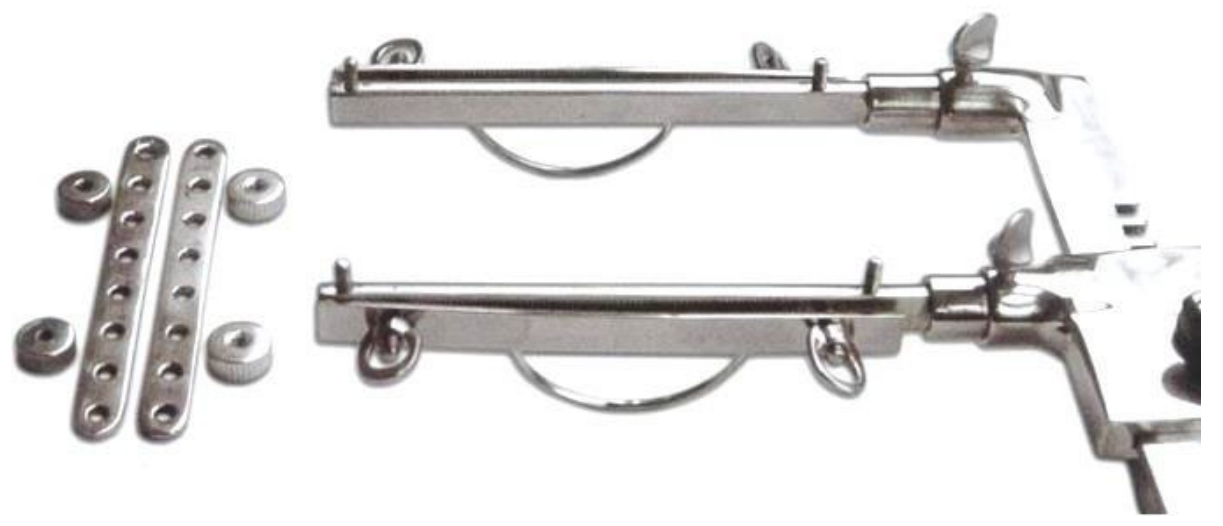

Fig. 1. General view of SPARC -III for rapprochement of the edges of a granulating wound in a prefabricated form with removable branches and spokes made in the form of curved surgical needles 
The ARA was removed after suturing in the 1 st series of the experimental group of animals, and in the $2^{\text {nd }}$ series, it remained on the wound for up to 3 days. In this case, the rack-and-pinion drive was removed. Capron No. 4 was used in control group, and sterilized and factory-packed suture material in experimental group No. 2.

Microbiological studies were carried out on the basis of the Research Institute of Epidemiology and Microbiology of the Ministry of Health of the Russian Federation. I.N. Blokhina. The consultant was the leading researcher at the Laboratory of Microbiology and Diagnosis of Dysbiosis, candidate of biological sciences E.V. Belyaeva in compliance with the order of the USSR Ministry of Health No. 535 of $04 / 23 / 85$. The range of studies included quantitative and qualitative determination of microflora. To quantify microorganisms, colony forming units (CFU) were counted with limiting dilutions per $1 \mathrm{ml}$ of wound, $1 \mathrm{~cm} 2$ of skin and $1 \mathrm{~cm}$ of suture. The skin and the animal's hair were studied in the area of purulent wound modeling, separated from the wound at the stage of purulent inflammation and regeneration, as well as suture material inside the tissues.

The "surface biopsy" method according to M.F. Kamaev (1970) was applied to cytological studies. Material for histological examination was taken immediately after suturing and on the 3rd day after suturing the wound. Cytological and histological studies were carried out in consultation with an assistant professor of the Department of Forensic Medicine and Pathological Anatomy of the Novosibirsk State Medical Academy A.A. Artifeksova.

The strength properties of the scar were studied by ranotensiometry method on the 3rd day after suturing of the granulating wound by a special device (Grechko V.N., 1993).

Experimental and clinical measurements of the elastic forces separating the edges of the soft tissue wound along its entire length were carried out by the dynamometric method (Ramazanov R.M., 1983; Izmailov S.G., 1994). The thickness of the tissues in the area of the wound sutured edges was measured with a caliper.

To assess the state of the microvascular bed around the wound during tissue tension, a study of the skin temperature was carried out in dynamics (Struchkov V.I., 1975). The skin temperature was measured with a TEN-5 electronic thermometer, manufactured in 2001 (Moscow), intended for use in medicine and veterinary with $0.1{ }^{\circ} \mathrm{C}$ resolution.

All animal operations were carried out in compliance with the order of the USSR Ministry of Health No. 755 of 08.22.77.

\section{Results and discussion}

The entire devices is subdivided according to the bringing together mechanism working part into the following main subgroups: 1 - spoke, 2 - lamellar, 3 filament, 4 - spoke and 5 - rod.

Depending on the wound location and shape, the RC are divided into: general (for all wounds) and special (for operations on the limbs, etc.). By appointment, the $\mathrm{RC}$ are divided into the following types: fixation (for gripping and holding tissues); hemostatic (for temporary, preventive or final stop of bleeding); immobilization; for the implementation of programmed rehabilitation of the pathological hotbed.

The most universal devices are SPARC with parallel holding of spokes relative to the axis of the wound. The goal of the work is to substantiate the use of curved knitting spokes in parallel by the methods of mathematical modeling. The feasibility of using bent knitting spokes is justified by the following circumstances.

We assume that the place of entry $A\left(A_{0}\right)$ and the place of exit $B\left(B_{0}\right)$ of these spokes coincide. Denote by $l$ the length of the straight spoke in the soft tissue, $l_{0}$ the length of the curved spoke in the soft tissue $\left(l_{0}>l\right)$ (Fig. 2).

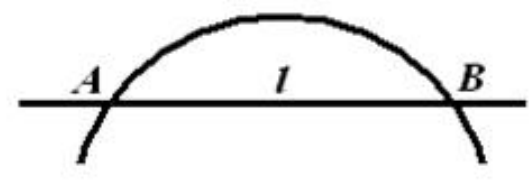

a)

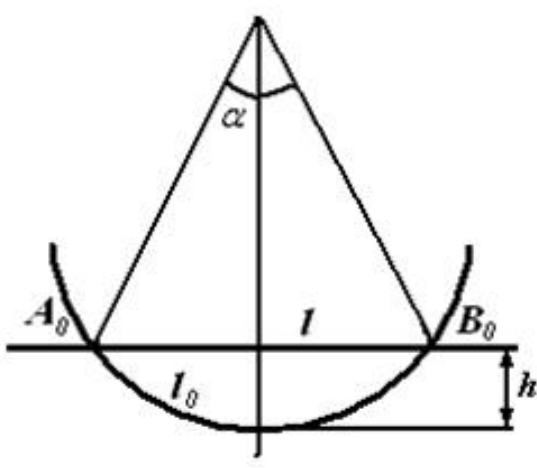

b)

Fig. 2. Two types of spokes

Consider two cases of spoke: straight and curved spokes (Fig. 2). Since most of the spoke is located in the soft tissue at the curved spoke, and not at the straight spoke, and given the formula

$$
q_{0}=\frac{P}{l_{0}}, q=\frac{P}{l}
$$

we obtain the following inequality

$$
\frac{q_{0}}{q}=\frac{l}{l_{0}}<1
$$

where $q_{0}, q$ are the pressures of the curved and straight spokes on the soft tissue respectively.

We carry out a numerical estimate of inequality (3). It is known that

$$
l_{0}=r \cdot \alpha, l=2 r \operatorname{Sin}(\propto / 2)
$$


Here $r$ is the radius of the curved spoke, $\alpha$ is the central angle in radians.

Find the $q_{0} / q$ ratio for different types of knitting spokes

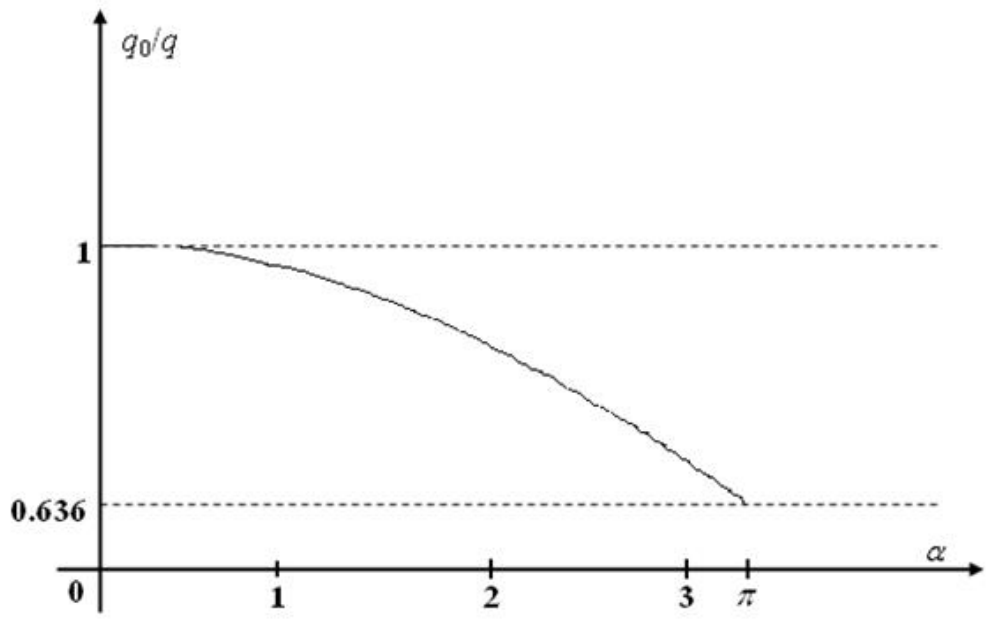

$$
\frac{q_{0}}{q}=\frac{l}{l_{0}}=\frac{\sin (\propto / 2)}{\propto / 2}
$$

Let us plot the relationship between the pressure ratio of the curved spoke and the straight spoke as a function of the central angle $\alpha$ of the curved spoke (Fig. 3).

Fig.3. The ratio of pressure on the soft tissue of a curved spoke to a straight line, depending on the central angle of the curved spoke

It can be seen from the graph that, as $\alpha$ increases, $q_{0} /$ $q$ decreases. In limiting cases, when $\alpha=\pi(h=l=r), q_{0}$ is less than $q$ by $36.34 \%$ (2.8 times).

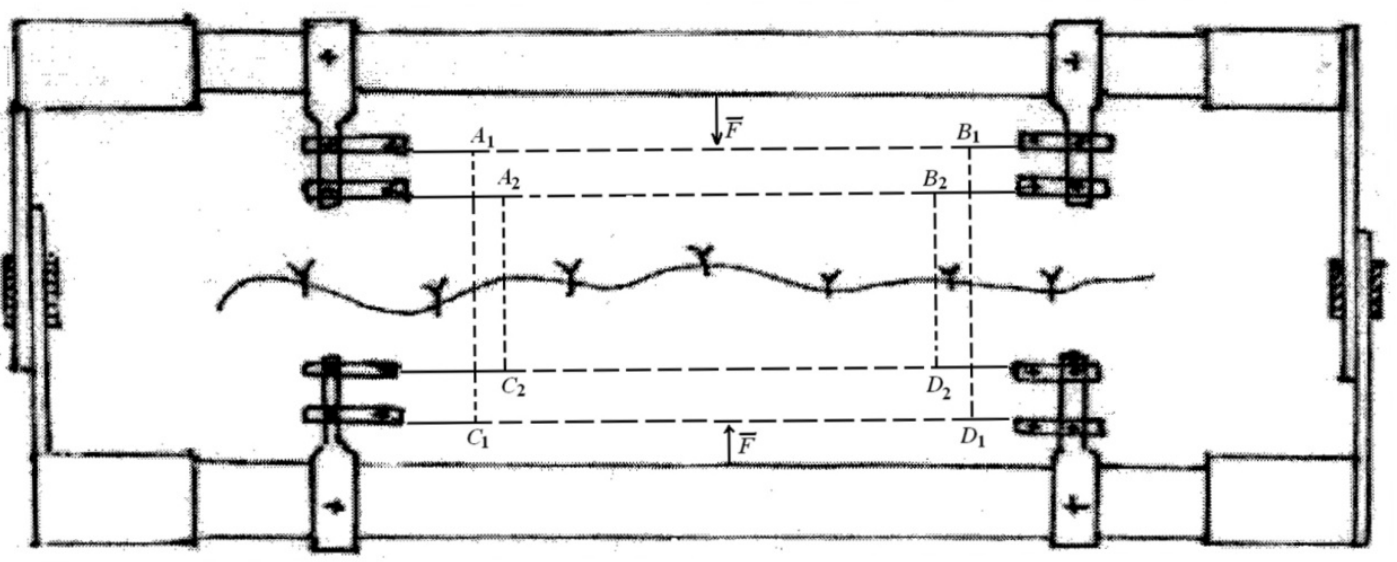

Fig. 4. Top view of the device
As an example, Fig. 3 shows two pairs of spokes $(\mathrm{N}=$ $2, \mathrm{~N}$ is the number of pairs of spokes). Here $A_{1}, A_{2}, C_{1}, C_{2}$ are the entry points of the spokes; $B_{1}, B_{2}, D_{1}, D_{2}$ - exit points of the spokes; $F[\mathrm{H}]$ - the total force acting from the side of the device on the tissue.

Let us evaluate the spokes pressure $q[\mathrm{H} / \mathrm{m}]$ to the tissue. We will consider two factors. First, an increase in the number of $\mathrm{N}$ pairs of spokes. Assuming that the length of the spoke in different pairs varies slightly, we can assume that the force $P$ acting on one spoke is

An increase the number $\mathrm{N}$ of pairs of spokes decreases their pressure $\mathrm{q}$ on the tissue $(q=P / l)$. For uniform pressure on the fabric, it is necessary to arrange the spokes at different depths and distances. It is necessary that the distance between the spokes is greater than their diameter $\mathrm{d}[\mathrm{m}]$, since they do not affect on the tissue at the distance greater than $\mathrm{d}$. approximately equal to $P=F / \mathrm{N}$.
Fig. 4 shows a top view of a schematic diagram of the proposed device
Second, deformation of the skin tissue and adjacen soft tissues at the points of entry / exit of the spoke occurs.

In places of entry / exit to the spoke, skin and adjacent soft tissues, $P / 2$ forces act (Fig. 5).

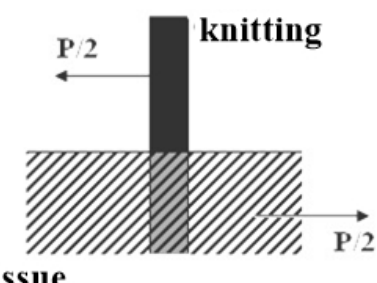

tissue

Fig. 5. The forces acting on the soft tissue during the knitting

Therefore, in the places of entry / exit of the spokes soft tissue is crushed. The creasing of the fabric will occur due to the tangential forces $\tau$, which are determined by the following expression 


$$
\tau=\frac{F}{N\left(\pi d^{2} / 2\right)}
$$

It follows from (6) that an increase in the number of spokes reduces the trauma of the skin at the points of entry and exit of the spokes.

Thus, the implementation of spokes in the form of curved surgical spokes in the form of $1 / 2-5 / 8$ of the diameter of the circle provides a deep and wide capture of tissues of the edges of the wound in a limited area. This reduces the morbidity of the wound edges and improve the adaptation of wound surfaces with deep soft tissue defects healing by secondary intention. Fixing SPARC-III to the skin with spokes in the form of surgical needles in 5/8 of the circle diameter allows the device to be used to reduce the edges of small wounds when the use of more bulky spoke devices is traumatic. An increase in the number of curved spokes, parallel to the branches and with the possibility of moving in horizontal and vertical directions, allows tissue traction at different levels determined by the depth of the spokes simultaneously or alternately turning on or off a pair of spokes, reduces tissue trauma to all layers of the wound edge.
The data obtained in an animal experiment confirmed mathematical calculations. Thus, the experimental studies showed that the closure of the granulating wound in the experiment (using hardware) occurred in more favorable conditions with the possibility of using precision technology and thin suture threads (Capron No. 2, thread diameter $0.25 \mathrm{~mm}$ ). In the control group of animals joining the wound edges was possible only when using Nylon thread No. 4 (thread diameter $0.45 \mathrm{~mm}$ ). With this diameter, the suture material retained its initial strength, and during visual inspection there were no signs of excessive threading of the tissue with the thread at the time of wound closure. The breaking load of the used suture material with a diameter of $0.25 \mathrm{~mm}$ and $0.45 \mathrm{~mm}$ was on average $(\mathrm{M} \pm \mathrm{m}) 9.9 \pm 1.2 \mathrm{~N}$ and $33.4 \pm 2.3 \mathrm{~N}$, respectively $(p<0.05)$. The use of RC completely excluded the "sawing" action of the thread observed with the traditional method of suturing. The experiments showed (table 1) that when using the RC, a stress distribution in the weld area that is safe in terms of healing is achieved.

Table 1. Comparative assessment of the thread tension force $\left(F_{\mathrm{H}}\right)$, normal $(\sigma)$ and tangential $(\tau)$ stresses, pressure $(P)$ of the edges of the wound against each other with different methods of suturing granulating wounds

\begin{tabular}{|c|c|c|c|c|c|c|}
\hline \multirow{2}{*}{ Suturing Method } & \multicolumn{2}{|c|}{$F_{\mathrm{H}}$ matching the wound edges, $\mathrm{N}$} & \multirow{2}{*}{$\begin{array}{l}F_{\mathrm{H}} \text { tightening the } \\
\text { seam assembly, } \mathrm{N}\end{array}$} & \multirow{2}{*}{$\sigma \cdot 10^{6} \mathrm{~Pa}$} & \multirow{2}{*}{$\tau \cdot 10^{6} \mathrm{~Pa}$} & \multirow{2}{*}{$\mathrm{P} \cdot 10^{6} \mathrm{~Pa}$} \\
\hline & central part & edge part & & & & \\
\hline Traditional & $18,1 \pm 0,6$ & $13,7 \pm 0,6$ & $34,1 \pm 0,7$ & $8,2 \pm 0,4$ & $1,5 \pm 0,2$ & $0,20 \pm 0,05$ \\
\hline Hardware & 0 & 0 & $2,0 \pm 0,1$ & $1,6 \pm 0,1$ & $0,10 \pm 0,02$ & $0,01 \pm 0,003$ \\
\hline $\mathrm{p}$ & $<0,01$ & $<0,01$ & $<0,01$ & $<0,01$ & $<0,01$ & $<0,01$ \\
\hline
\end{tabular}

According to electro thermometry, the average skin temperature of healthy tissues in the wound area in the control group was $(\mathrm{M} \pm \mathrm{m}) 29.7 \pm 0.3^{\circ} \mathrm{C}$, and in the main group $29.8 \pm 0.2^{\circ} \mathrm{C}(\mathrm{p}>0.05)$ In the stage of purulent inflammation, the temperature of the perivular zone in the area of the purulent wound decreased $(p<0.05)$ to $26.2 \pm$ $0.2^{\circ} \mathrm{C}$ and $26.1 \pm 0.1^{\circ} \mathrm{C}$, respectively, and in the regeneration phase before suturing it reached the initial values $(29.7 \pm 0.4$ and $29.4 \pm 0.3$, respectively). In the control group, when wounds were sutured in the traditional way, when the sutures were tightened and the edges of the wound were tensioned, the skin temperature in the area of the suture line decreased by an average of $1.8 \pm 0.4{ }^{\circ} \mathrm{C}(\mathrm{p}$ $<0.05)$, and in the experimental group compared to the initial ones figures on average $0.6 \pm 0.1^{\circ} \mathrm{C}(\mathrm{p}<0.05)$. The differences between the gradients of temperature reduction in the control and experiment are statistically significant $(\mathrm{p}<0.05)$.

It was found that when suture material was passed through the tissue of a granulating wound, in $100 \%$ of cases of both experimental and control groups of animals, suture material was contaminated. Most often, S.epidermidis was found in the studied material in a monoculture or in associations with S.aureus and E.faecium, and the average microbial number averaged in the experimental group $(3.4 \pm 0.8) \cdot 101 \mathrm{CFU} / \mathrm{cm}$ suture and $(3.3 \pm 0.8) 101 \mathrm{CFU} / \mathrm{cm}$ - in the control. Three days after suturing, the number of microorganisms on the suture in the experiment did not significantly increase from the statistic and averaged $(4.1 \pm 0.7) 101 \mathrm{CFU} / \mathrm{cm}$. At the same time, in the animals of the control group there was a significant increase in the number of microorganisms to (3.5 \pm 0.6) $105 \mathrm{CFU} / \mathrm{cm}$. Moreover, an increase in bacterial contamination of suture material was accompanied by an increase in the frequency of detection of pathogen associations on suture material in this group of animals. The studied state of the wound edges tissue in the subsequent healing periods showed that wound complications occurred more often in the control group than in the experimental group. So, on the 3rd day after suturing in 4 of 6 animals of the control group, purulentinflammatory complications (infiltrates, suppuration of the wound, teething) from the side of the wound were clinically observed. All animals in the control group revealed partial eruption of sutures. In 2 series of the experimental group, only in 1 case out of 12 there was suppuration of the postoperative wound in a limited area, requiring removal of 1 suture (rTMP $<0.05)$. In the remaining 11 observations, wound healing was of the type of primary tension.

The wound tensiometry showed that at the 3rd day after suturing the experimental group the average rupture of the scar was $(\mathrm{M} \pm \mathrm{m}) 21.7 \pm 0.6 \mathrm{kPa}$ in 1 series and 22.6 $\pm 0.5 \mathrm{kPa}$ in $2-$ th and was respectively 1.6 and 1.7 times higher $(\mathrm{p}<0.05)$ than in the control group $(13.6 \pm 1.0 \mathrm{kPa})$. The differences between the first and second series in the experimental group are statistically insignificant $(\mathrm{p}>0.05)$.

The histology confirmed the results obtained by tensiometry at the microscopic level. Zones of primary alteration were found in the entire control group of animals immediately after suturing of the granulating wound in a cross section of the suture area, the tissue was teething 
while reducing the wound edges and tightening the knot. With a hardware method for wound suturing, the alteration zone was limited only by the diameter of the thread without additional eruption of tissue. Compared with the control group of animals, large hotbeds of necrotic changes were not detected. At the same time, the structure of surrounding tissues was preserved.

Three days after suturing by the traditional suturing method vertical and horizontal sections around the suture threads showed signs of massive tissue destruction in the form of large necrosis fields saturated with purulent exudate. In this case, not only tissues bordering the channel of the thread were exposed to necrosis, but also distant areas located on the line of tension of the thread. The cause of these necrosis could be both the mechanical effect of the thread on the surrounding tissue during contraction of the wound edges (direct necrosis), and vascular disorders in distant areas in the form of sweets, blood clots (indirect vascular necrosis). The intracanalicular pathway of infection spread is obvious, since leukocytes were found not only at the edges of the thread channel, but also in the channel itself, as well as between the elements of the thread.

In the granulating wound, which was sutured by hardware, the cellular infiltration of stitched tissues was significantly less compared to the control, which indicated a weak severity of the inflammatory reaction.

Thus, the conducted experimental studies have established that the convergence of the rigid edges of the granulating wound using the suture in the traditional way under the conditions of tensile forces, the tightening of the sutures leads to the formation of primary hotbed of necrosis in the sutures and edges of the wound, intraoperative eruption of the suture, hemorrhages and reduced vascularization of stitched tissues. This is the reason for the decrease in local resistance of tissues to infection, their regenerative ability, which creates unfavorable conditions for the course of the wound process and thereby significantly increases the risk of purulent-inflammatory wound complications even in conditions of low microbial contamination of the wound surface, when the number of microbial bodies does not exceed the critical level $10^{5} \mathrm{CFU}$.

In contrast to the traditional suturing method the closure of the granulating wound using the $\mathrm{RC}$ is carried out without suture thread. The latter is used only to keep the edges of the wound defect at a reduced state. This achieves anatomically accurate reconstruction of tissues in the wound area, minimal damaging effect on stitched tissues, complete elimination of the "sawing" effect of the thread and its eruption at the moment of matching the wound edges. In addition, optimal conditions are provided for adequate blood supply in the area of a wound defect. This increases the resistance of local tissues to infection and reduces the risk of wound suppurative inflammatory complications.

When modeling the process of suturing a wound, an important step is the selection of a soft tissue model. Some existing models created for different purposes were analyzed: finite element model [1], various point models [4-6]. In [7], the advantages and disadvantages of these representations of soft tissue for modeling were described.
Based on the analysis of numerous studies in various industries, the authors of $[2,8]$ propose a generalized formulation of the Stretched Grid Method (SGM), which is a kind of grid methods that allows very efficient modeling of the behavior of equilibrium continuum by representing it as an energy-equivalent grid structure. The generalized formulation assumes the presence of external influences on the system in the form of superimposed elastic nodal bonds and nodal pseudo-loads, which allows us to simulate external constrains and continuum loads, namely

$\Pi=\sum_{j=1}^{n} D_{j} R_{j}^{2}+\sum_{i=1}^{3}\left(\sum_{k=1}^{m} C_{i k}\left(\Delta X_{i k}\right)^{2}-\sum_{k=1}^{m} P_{i k} \Delta X_{i k}\right), \quad$ (7) where $n$ is the total number of mesh segments, $m$ is the total number of mesh nodes, $R_{j}$ is the length of segment number $j, D$ is the stiffness of the segments (assumed to be the same for all), $\Delta X_{i k}$ is the increment of the coordinate of the kth node along the $i$ axis, $C_{i k}$ is stiffness of the elastic bond in the node number $k$ along the $i$-axis, $P_{i k}$ - external load in the node number $k$ along the $i$-axis.

It is assumed that soft tissue is a continuum modeled by an equivalent grid structure, which is a set of point masses connected by springs. In [4-6], the following law of motion was obtained for node number $i$ of the nodalspring model

$\mu \frac{d^{2} r_{i}}{d t^{2}}=-\gamma \frac{d r_{i}}{d t}+\sum_{j \in N(i)} K_{i, j} \frac{\left(l_{i, j}^{0}-\left\|r_{i} r_{j}\right\|\right) r_{i} r_{j}}{\left\|r_{i} r_{j}\right\|}$,

where $\mu$ is the mass of the point, $\gamma$ is the damping coefficient, $K_{i, j}$ is the stiffness coefficient of the spring connecting the $i$ and $j$ points, $N(i)$ is the set of points connected to this, $l^{0}{ }_{i, j}$ is the distance between the $i$ and $\mathrm{j}$ points in an unstressed state.

Minimization of functional (7) with respect to unknown nodal changes in the coordinates of the points allows obtaining a relationship that differs from equation (8) only in the inertial term on the left equation side and the first term on the right, which reflects the damping properties of the tissue model. Thus, SGM allows the formation of a nodel-spring model that is in good agreement with those developed earlier. The advantage of SGM is in solving the problem in a quasi-static setting, which greatly simplifies the solution of the problem. This formulation can be used in both static and dynamic settings. Minor modifications of relation (7), related to the inertial and damping components allows obtaining the corresponding equations of motion of an elastic grid with point masses, which can be solved using step-by-step algorithms. Modeling of cuts and seams is done by removing or creating bonds between the corresponding point masses.

When using a grid structure with point masses for modeling soft tissue the following problems need to be solved

1. The bonds topology. The number and arrangement of bonds between the masses greatly affects the behavior of the entire system. If the number of bonds is insufficient or there are too many of them, the model will not reflect the actual behavior of the soft tissues. Because of these they are usually limited to a regular lattice structure.

2. Physic-mechanical properties of grid segments. The problem lies in determining the bond properties 
between the masses for the correct modeling of soft tissues.

The model for studying the process of suturing a wound using $\mathrm{RC}$ is a regular $3 \mathrm{D}$ grid with point masses in nodes, which represents soft tissues of various properties. Bonds between nodes between nodes have only tensilecompression rigidity and act as springs. Three main aspects can be distinguished that affect the consistency of the real tissue model

1. Nodes of regular grid. Different masses of nodes model different layers of tissue that have different density.
2. The grid topology. The hexagonal regular grid structure is not enough. Therefore, additional diagonal bonds were added (see Fig. 6).

3. Grid bond properties. Different elastic parameters for bonds between point masses can be applied to simulate different layers of different tissue elasticity. In [1] data of the tissue elasticity obtained by vibroelastometry. These data were used to set the quantitative characteristics of model grid correctly.

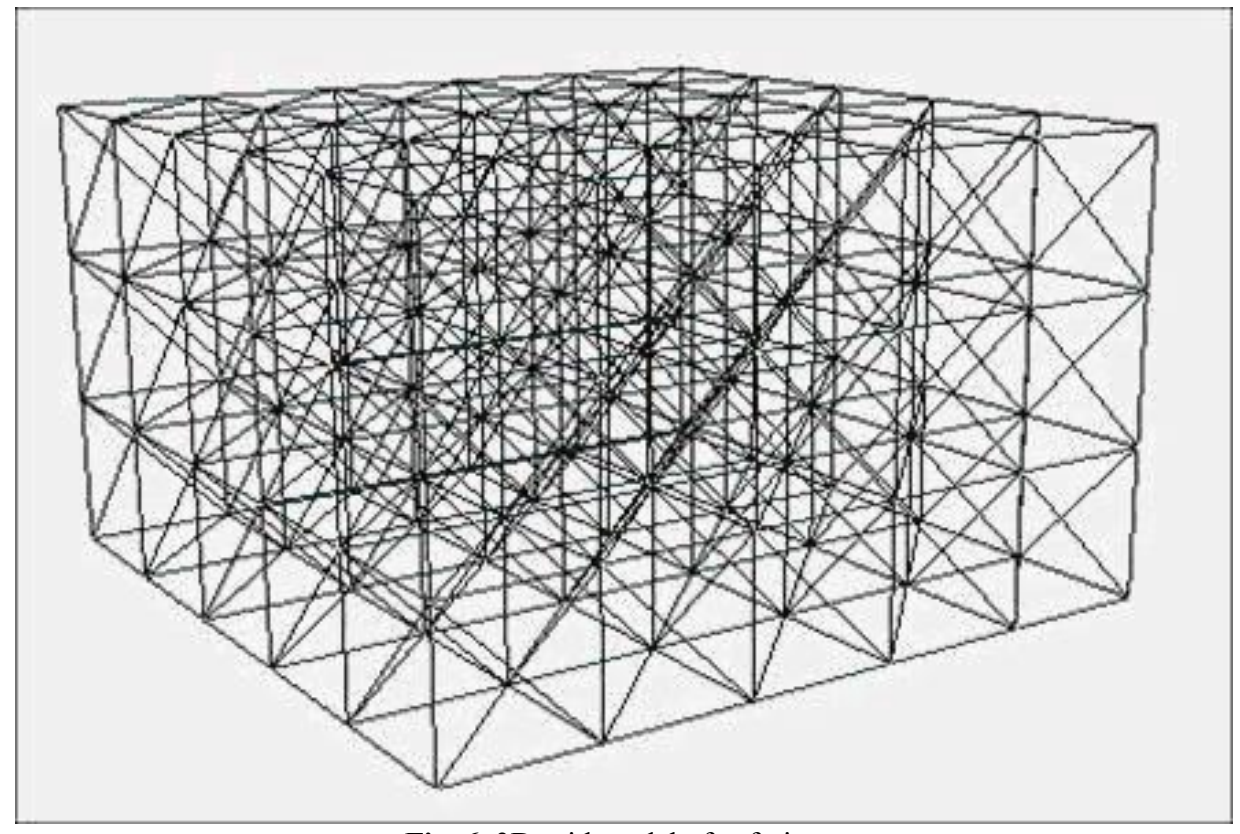

Fig. 6. 3D grid model of soft tissue

To simulate the process of wound suturing it is necessary to simulate an incision of the desired size and shape. In our grid tissue model this can be done by eliminating the bonds between the corresponding nodal masses. The cut is formed automatically due to the tension in the tissue itself.
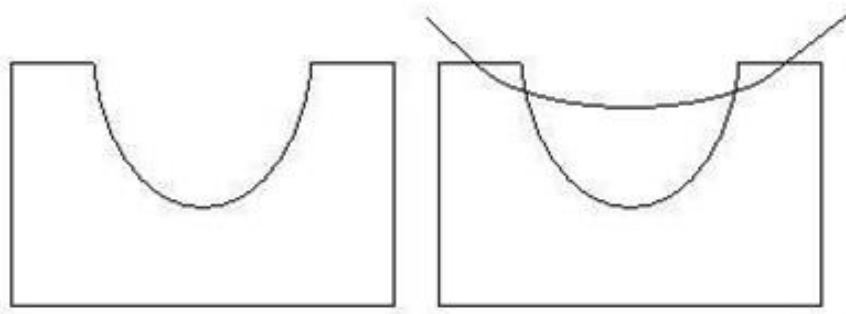

Fig. 7. Converging the wound edges by RC

In order to simulate the converging of the wound edges the corresponding nodes in the regular grid are declared to belong to spokes or branches. In this case, all connections with these nodes are saved. Next, you need to set the trajectory and speed of these nodes. Thus, the deformation of tissues during the straightening of spokes can be determined by comparing the geometry of the undeformed and deformed grid, taking into account the physical and mechanical properties of the grid segments.
The approach of the wound edges by $\mathrm{RC}$ is schematically shown in Fig. 7. and consists of the following steps:

1. The intrusion of special curved spokes into the tissue.

2. Straightening spokes.

3. Converging of the edges of the wound with the help of branches on the spokes.
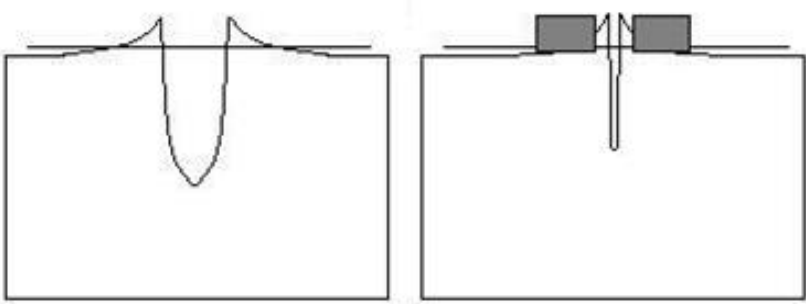

The knowledge obtained on the basis of this mathematical model of wound closure by various RC options allows optimizing the constructive part of devices for their more effective practical application.

An analysis of patient's treatment with granulating wounds showed that the use of RC with perpendicular holding of spokes and needles can lead to cosmetic defects due to the frequency of purulent-inflammatory complications with overall good and satisfactory healing. This was confirmed by our research in the mathematical 
modeling of the process of suturing soft tissue wounds. Significantly fewer complications were observed when using the $\mathrm{RC}$ with parallel edges of the wound using curved knitting needles (22.6\% and $11.8 \%$, respectively). Purulent-inflammatory complications developed in $17.1 \%$ with hardware and in $59 \%$ of cases with the traditional method of suturing $(\mathrm{p}<0.05)$.

The hardware application to the treatment of abdominal hernias reduced the number of postoperative wound complications from 29.1 to $10.3 \%$ ( $<<0.001)$, the number of complications from the bronchopulmonary and cardiovascular systems from 11.4 to $4 \%(\mathrm{p}<0.005)$, the number of relapses from 15.8 to $1.9 \%$ ( $p<0.001)$, which can primarily be explained by a decrease in the trauma of stitched tissues and the reliability of closing a wound defect.

\section{Conclusion}

The wound edges convergence is a preparatory operation for suturing. However, in such a formulation it is already possible to give not only a qualitative, but also a quantitative assessment of the clinical efficacy of different RC constructs. To do this, it is necessary to develop an algorithm for assessing the damage that tissue receives when various wound devices are applied to it.

The next step in modeling should be the wound suturing in the state after applying the RC. The developed mathematical model can be used for subsequent optimization of wound suturing technology in a clinical setting.

The developed mathematical model is applicable for studying the process of suturing a wound using $\mathrm{RC}$ from beginning to end.

\section{Acknowledgment}

The work was performed according to the RFBR grant No. 19-07-01024.

\section{Reference}

[1] Pisarenko, G.S. Spravochnik po soprotivleniyu materialov / G.S. Pisarenko, A.P. YAkovlev, V.V. Matveev. - Kiev: Naukova Dumka, 1975. - 704 s.

[2] Feodos'ev, V.I. Soprotivlenie materialov / V.I. Feodos'ev. - M.,1970. - 544 s.

[3] Chernyh, K.F. Nelinejnaya teoriya uprugosti v mashinostroitel'nyh raschetah/ K.F. CHernyh. - L.: Mashinostroenie, 1986. - $336 \mathrm{~s}$.

[4] Efimenko, N.A. Plasticheskaya i rekonstruktivnaya hirurgiya $v$ lechenii ognestrel'nyh ranenij / N.A. Efimenko, A.A. Gricyuk, S.M. Rybakov i dr.// Aktual'nye problemy travmatologii i ortopedii: Materialy nauch. konf., provodimoj v ramkah mezhdunar. foruma «CHelovek i travma». - CHast' 1. Nizhnij Novgorod, 2001. - S. 149-150.

[5] Izmajlov, S.G. Apparatnaya tekhnika v lechenii gnojnyh ran/ S.G. Izmajlov, V.V. Beschastnov, A.A. CHirkin, A.I. Rotkov i dr. - Kazan', 2007. - 92 s., ill.

[6] Bazanov, K.V., Effektivnost' biomekhanicheskogo modelirovaniya abdominoplastiki v lechenii posleoperacionnyh ventral'nyh gryzh: diss.kand.med. nauk. - Nizhnij Novgorod: NGMA, 2000. - 214s.
[7] Popov, E.V. Metod natyanutyh setok v zadachah geometricheskogo modelirovaniya: diss. d-ra tekhn. nauk. - Nizhnij Novgorod: NNGASU, 2001. -350s.

[8] Svetuhin, A.M. Etiopatogeneticheskie principy hirurgicheskogo lecheniya gnojnyh ran / A.M. Svetuhin, V.M. Matasov, V.G. Istratov i dr.// Hirurgiya, - 1999.-№ 1.- S. 9-11.

\section{About the authors}

Izmailov Sergey G., MD, professor, State Clinical Hospital No.35, Nizhny Novgorod. E-mail: izi28082009@yandex.ru Rotkov Andrey I., candidate of medical sciences, associate professor, State Clinical Hospital No. 35, Nizhny Novgorod. Email: 3959400@mail.ru

Beschastnov Vladimir V., MD, Associate Professor, State Clinical Hospital No. 35, Nizhny Novgorod. E-mail: vvb748@mail.ru

Rotkov Sergey I., Doctor of Technical Sciences, Professor, Nizhny Novgorod State University of Architecture and Civil Engineering, Nizhny Novgorod. E-mail: rotkov@nngasu.ru

Popov Evgeny V., Doctor of Technical Sciences, Professor, Nizhny Novgorod State University of Architecture and Civil Engineering, Nizhny Novgorod. E-mail: popov4487@yandex.ru

Lukoyanychev Egor E., candidate of medical sciences, associate professor, State Clinical Hospital No. 35, Nizhny Novgorod. E-mail: egor-lukoyanychev@yandex.ru 